CARPIO, R. C. et al. Análise teórica da recuperação de calor para geração de energia em indústrias de cimento e cal utilizando o Ciclo de Rankine Orgânico

\title{
ANÁLISE TEÓRICA DA RECUPERAÇÃO DE CALOR PARA GERAÇÃO DE ENERGIA EM INDÚSTRIAS DE CIMENTO E CAL UTILIZANDO O CICLO DE RANKINE ORGÂNICO
}

\author{
Ricardo Carrasco Carpio ${ }^{1}$ \\ Leandro de Souza Lemos ${ }^{2}$ \\ Carlos Antônio Rufino Junior ${ }^{3}$ \\ Vanessa dos Santos Sousa ${ }^{4}$
}

\begin{abstract}
RESUMO
O presente trabalho consiste em uma apresentação do estado da arte do Ciclo Rankine Orgânico, um ciclo termodinâmico que usa um fluido orgânico como fluido de trabalho e que pode ser usado para recuperação de calor rejeitado em processos industriais, gerando assim energia elétrica para abastecer a própria indústria, o que consequentemente causa uma redução no custo de produção da empresa. São apresentados alguns fluidos orgânicos e alguns de seus parâmetros termodinâmicos.
\end{abstract}

Palavras-chave: Cogeração. Ciclo Rankine Orgânico. Fluidos de Trabalho.

\section{THEORETICAL ANALYSIS OF HEAT RECOVERY FOR POWER GENERATION IN CEMENT AND LIME INDUSTRIES USING THE ORGANIC RANKINE CYCLE}

\begin{abstract}
This work aims to present the state of the art of the Organic Rankine Cycle, a thermodynamic cycle that uses an organic fluid as a working fluid that can be used to recover the rejected heat in industrial processes, thus generating electricity to supply industry itself, which causes a reduction in the production cost of the company. It also presents some organic fluids and some of their thermodynamic parameters.
\end{abstract}

Keywords: Cogeneration. Organic Rankine Cycle. Working Fluids.

\footnotetext{
${ }^{1}$ Doutor em Engenharia Mecânica pela Universidade Federal de Itajubá (UNIFEI). Secretário de Extensão, Pesquisa e Pós-graduação do Instituto Federal de Minas Gerais (IFMG) - Campus Formiga. E-mail: ricardo.carrasco@ifmg.edu.br.

${ }^{2}$ Graduando em Engenharia Elétrica pelo IFMG - Campus Formiga. E-mail: geomanc3r@hotmail.com.

3 Graduando em Engenharia Elétrica pelo IFMG - Campus Formiga. E-mail: junin.udia@hotmail.com.

${ }^{4}$ Graduanda em Engenharia Elétrica pelo IFMG - Campus Formiga. E-mail: val_santos.1@hotmail.com. ForSci.: r. cient. IFMG campus Formiga, Formiga, v. 3, n. 1, p. 18-30, jan./jun. 2015.
} 
CARPIO, R. C. et al. Análise teórica da recuperação de calor para geração de energia em indústrias de cimento e cal utilizando o Ciclo de Rankine Orgânico

\section{INTRODUÇÃO}

A questão energética tem um significado relevante no contexto ambiental e na busca pelo desenvolvimento sustentável. A crescente demanda por formas limpas de se produzir energia promove a busca pela redução do uso de combustíveis fósseis como fontes de geração. Segundo o balanço energético nacional - Ben (2012) - feito pela Empresa de Pesquisa Energética - EPE (2012), pode-se verificar as fontes primárias de produção de energia na FIG. 1.

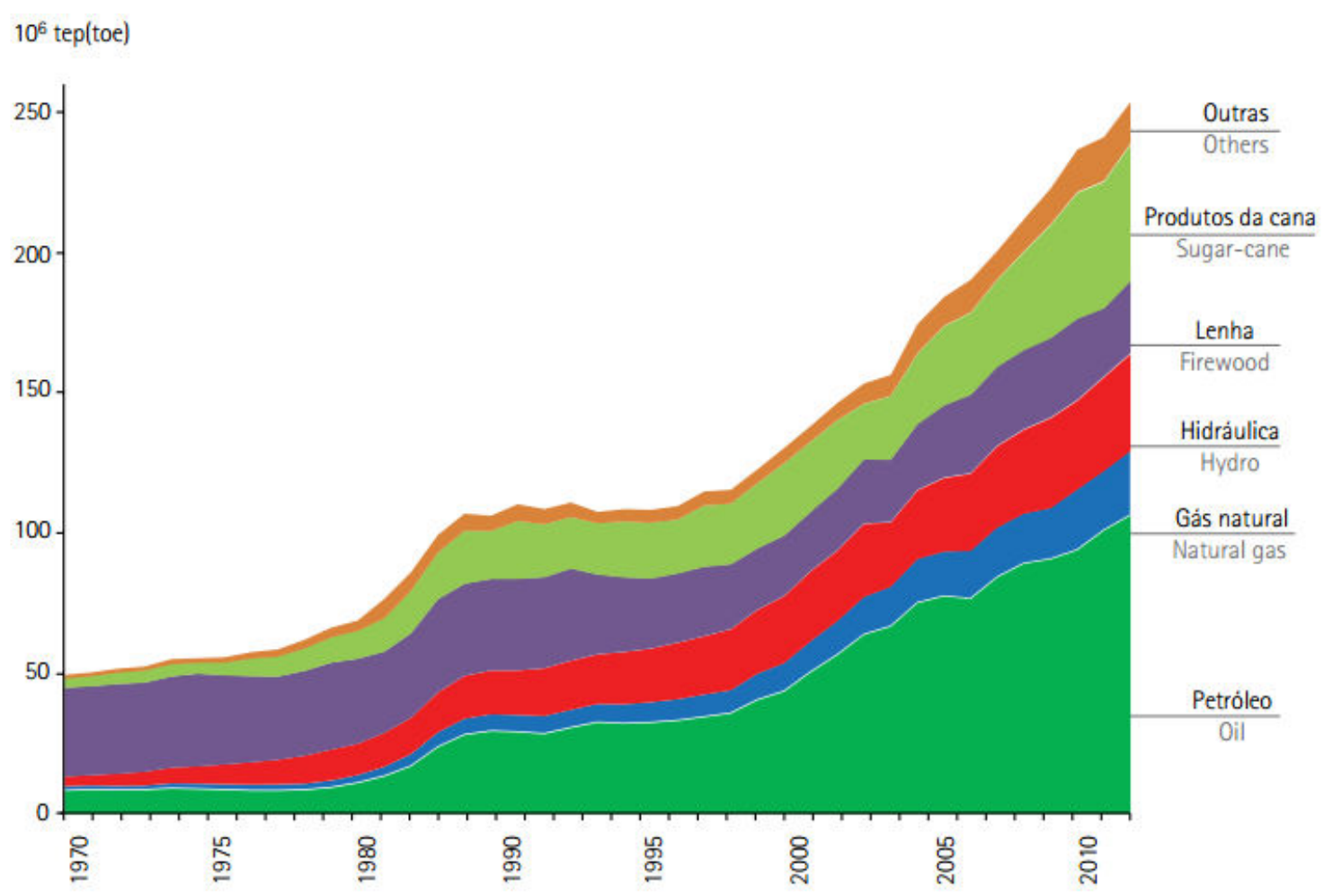

Figura 1- Produção de energia por meio de fontes primárias Fonte: Ben (2012).

Fontes primárias de energia são aquelas encontradas na natureza na forma de recursos naturais; enquanto fontes secundárias são aquelas para as quais a energia primária pode ser convertida.

De acordo com a Figura 1, houve um crescimento entre 1970 e 2012 no uso de fontes primárias renováveis, como biomassa e hidráulica. Porém, também se nota um aumento considerável do uso de fontes não renováveis, como a utilização de derivados do petróleo para produzir energia. 
CARPIO, R. C. et al. Análise teórica da recuperação de calor para geração de energia em indústrias de cimento e cal utilizando o Ciclo de Rankine Orgânico

Entre todas as formas secundárias de energia, a energia elétrica se mostra a mais versátil, inserindo-se na vida moderna e colaborando com o desenvolvimento da sociedade. As fontes de geração de energia elétrica no País podem ser vistas na FIG. 2.

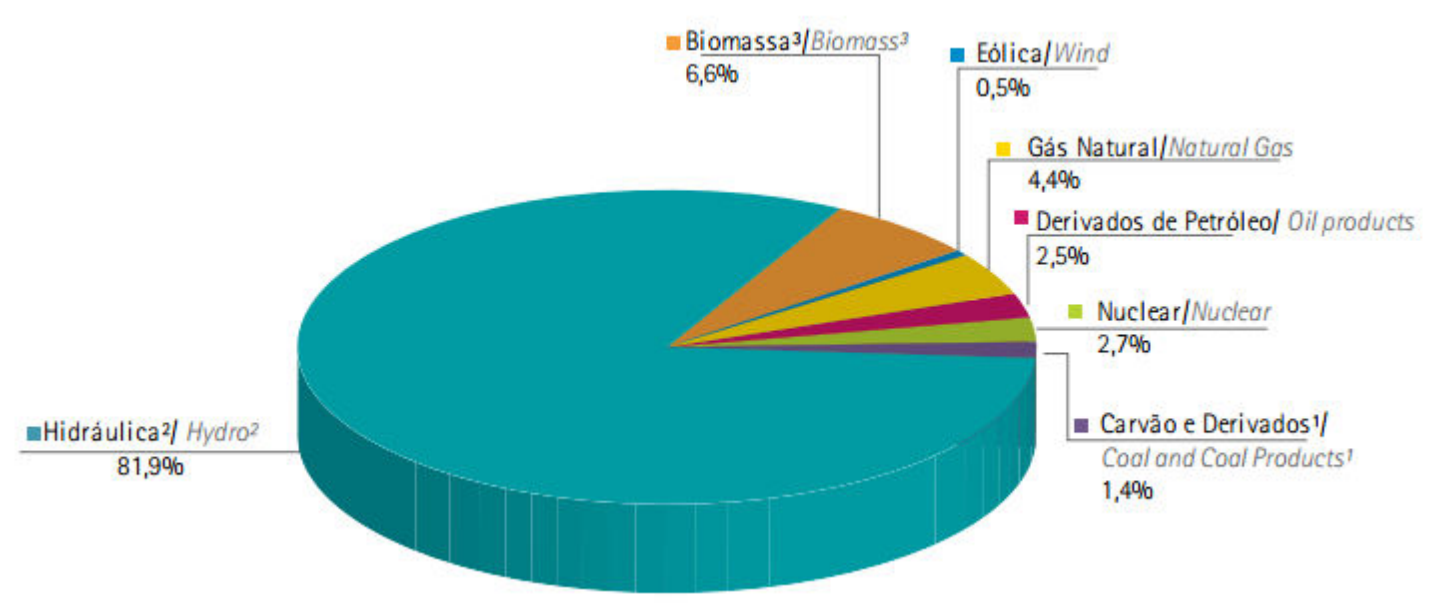

Figura 2 - Oferta interna de energia elétrica por fonte.

Fonte: Ben (2012).

Verifica-se que o Brasil possui uma matriz energética predominantemente renovável, principalmente de origem hidráulica. Apesar de ser considerada uma fonte limpa de energia, o setor energético produz impactos ambientais em toda a sua cadeia de desenvolvimento, desde a captura de recursos para sua produção, sua distribuição e seu uso pelos consumidores finais (REIS, 2011).

Nas indústrias, a forma mais comum de fornecimento de energia elétrica é por meio da compra da concessionária local, ou gerada pela queima de combustíveis. Porém, a geração de eletricidade é uma das formas mais rentáveis e eficientes em uma planta, principalmente se feita por meio do aproveitamento de fluxos térmicos rejeitados durante o processo produtivo, o que pode representar entre $60-80 \%$ do total da fonte primária de energia utilizada. Segundo Galanis et al. (2009), no Canadá os oito maiores setores industriais rejeitam ao ambiente $70 \%$ do total da energia consumida por eles. No Brasil, o setor industrial consome em torno de $880.000 \mathrm{GW}$ anualmente, dos quais aproximadamente $25 \%$ são atribuídos aos processos produtivos de fabricação de cimento, cal e aço.

O estado de Minas Gerais possui uma das maiores reservas minerais do País, sendo comprovada a existência de jazidas de calcário (produto principal da fabricação de cal e cimento) em diversos municípios e regiões do Estado, o que faz de sua exploração uma importante atividade econômica. Atualmente, Minas Gerais é o maior produtor de cimento do 
CARPIO, R. C. et al. Análise teórica da recuperação de calor para geração de energia em indústrias de cimento e cal utilizando o Ciclo de Rankine Orgânico

Brasil, com 23,54\% da produção nacional concentrada em suas 14 fábricas, que produzem 11,3 milhões de toneladas anuais (CARPIO, 2005).

No entanto, o processo de fabricação da cal e do cimento demanda grande quantidade de energia, representada principalmente pelo consumo de combustível nos fornos para converter o calcário em cal ou clinquer (principal elemento do cimento) e em energia elétrica durante os processos de britagem e moagem das matérias-primas. Durante esses processos produtivos, uma grande parcela da energia é rejeitada ao ambiente em forma de calor, por meio dos gases de combustão e ar de resfriamento do clinquer. Essa energia pode ser aproveitada para gerar energia elétrica a um custo aceitável, com o intuito de atender parte da demanda de energia elétrica consumida pela indústria, aumentando a rentabilidade e eficiência do processo produtivo pela otimização no uso dos recursos energéticos.

\section{COGERAÇÃO}

Uma forma de minimizar perdas de calor em processos industriais é aproveitar o fluxo energético que seria desperdiçado para o meio ambiente gerando energia elétrica.

Este aproveitamento de fluxo energético para gerar eletricidade é chamado de cogeração, e embora o País já utilize esse sistema há décadas, devido à acentuada expansão no sistema elétrico brasileiro nos anos 1950, formado principalmente por recursos hídricos, a cogeração despertou pouco interesse em investidores. A venda do excedente de energia elétrica também era desfavorecida pelas baixas tarifas oferecidas nos contratos. Atualmente, a cogeração apresenta expectativas de expansão, e as unidades cogeradoras no Brasil possuem capacidade de aproximadamente 1,8 GW (LORA, 2004). Para que seja viável o emprego de algum módulo de recuperação de calor, deve ser feita uma análise técnica e financeira da planta.

Uma das tecnologias empregadas na recuperação de calor é a utilização do Ciclo Rankine Orgânico, que gera energia elétrica empregando fluidos térmicos orgânicos, diferentemente do Ciclo Rankine comum, que é utilizado amplamente em centrais termelétricas tradicionais, onde o fluido de trabalho é a água. Embora o princípio de funcionamento seja igual, fluidos orgânicos possuem limites de saturação inferiores aos da água, exigindo menores capacidades caloríficas para saturar. 
CARPIO, R. C. et al. Análise teórica da recuperação de calor para geração de energia em indústrias de cimento e cal utilizando o Ciclo de Rankine Orgânico

\section{CICLO RANKINE}

O ciclo convencional Rankine (CR) é uma abordagem prática do ciclo termodinâmico ideal (ciclo de Carnot), no qual o vapor de água superaquecido é gerado em uma caldeira para logo ser expandido numa turbina para gerar trabalho de eixo ou potência elétrica por meio de um gerador. O vapor remanescente é condensado e reciclado para a caldeira para continuar o ciclo (ROY et. al., 2010). A Figura 3 ilustra o processo do ciclo Rankine.

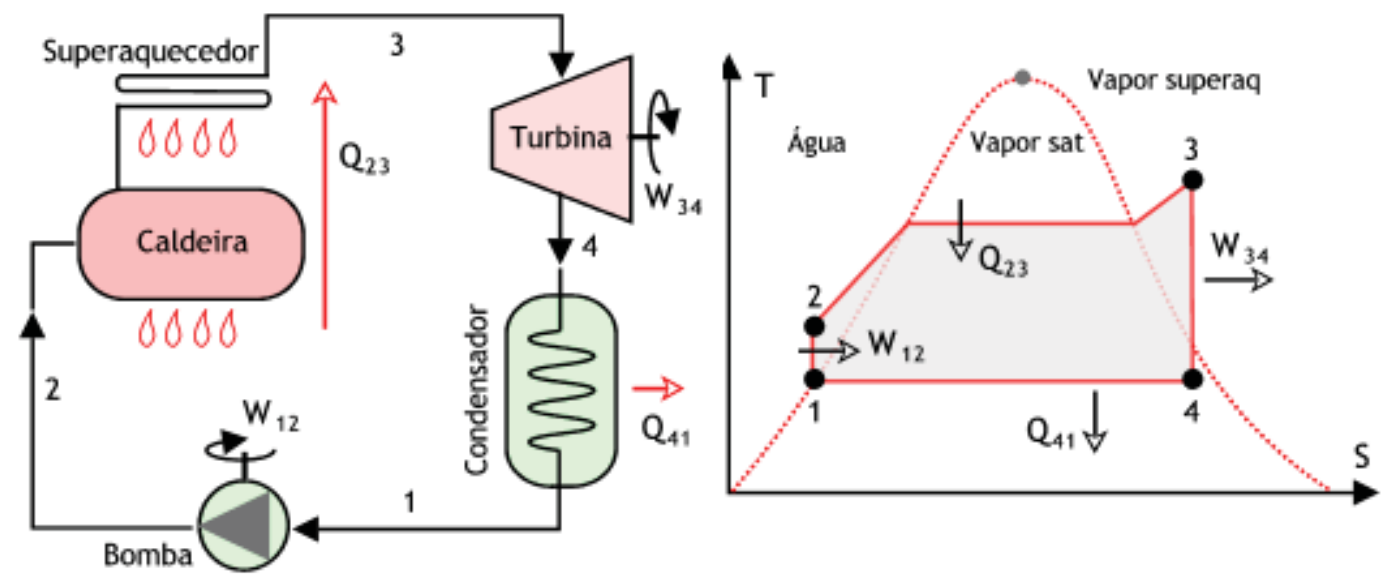

Figura 3- Fases do ciclo de Rankine e diagrama $\mathrm{T}$ x S do ciclo Fonte: Vicentini (2011 apud SOARES, [s.d]).

Podem-se considerar os seguintes componentes no ciclo da Figura 3:

- Bomba - processos de 1 a 2

- Caldeira ou trocador de calor - estágios de 2 a 3

- Turbina - estágios de 3 a 4

- Condensador - processos de 4 a 1

Uma turbina a vapor em um ciclo Rankine possui diversos estágios de expansão. Em cada um deles, o fluido sofre um decaimento de pressão. Nos estágios onde a pressão é baixa, as pás da turbina podem sofrer erosão proveniente da condensação de vapor. Isso ocorre porque as gotas de água possuem densidade maior que o vapor e, portanto, elevada energia cinética, que pode causar danos à turbina. Para minimizar esse efeito na entrada da turbina, o vapor é sobreaquecido, para que o risco de condensação seja minimizado. 
CARPIO, R. C. et al. Análise teórica da recuperação de calor para geração de energia em indústrias de cimento e cal utilizando o Ciclo de Rankine Orgânico

\subsection{Equacionamento de um ciclo Rankine}

Para o equacionamento de um ciclo Rankine ideal, considera-se que:

- Os processos são irreversíveis;

- Quedas de pressão, devido ao atrito, são ausentes na caldeira e no condensador, logo o fluido de trabalho passa por estes componentes com pressão constante;

- Os processos por meio da turbina e da bomba são isentrópicos.

Segundo Shapiro et al. (2005), as análises de cada processo do ciclo da Figura 3 podem ser realizadas da seguinte forma:

Processo 1-2- Bombeamento adiabático reversível. O líquido condensado, ao deixar o condensador, é bombeado para a caldeira em uma pressão mais elevada. Uma análise do processo pela primeira lei da termodinâmica fornece a equação (1):

$$
w_{12}=h_{2}-h_{1}
$$

Onde:

$\mathrm{w}_{12} \rightarrow$ trabalho realizado pela bomba [J.s/kg]

$\mathrm{h} \rightarrow$ valor de entalpia específica no ponto correspondente $[\mathrm{J} / \mathrm{kg}]$

Por requisitar energia do meio externo para realizar trabalho, a expressão (1) tem valor negativo no cálculo de eficiência do ciclo.

Processo 2-3: Transferência de calor em pressão constante na caldeira. O líquido que sai da bomba é aquecido até a saturação e evaporado nesse processo, considerando um volume de controle envolvendo os tubos e dutos da caldeira ou trocador de calor que transportam o líquido. Uma análise do processo pela primeira lei da termodinâmica fornece a equação (2):

$$
\boldsymbol{q}_{23}=\left(\boldsymbol{h}_{3}-\boldsymbol{h}_{2}\right)
$$

Onde:

$\mathrm{q}_{23} \rightarrow$ Fluxo de calor específico transferido ao sistema pela caldeira [J.s/kg] 
CARPIO, R. C. et al. Análise teórica da recuperação de calor para geração de energia em indústrias de cimento e cal utilizando o Ciclo de Rankine Orgânico

Processo 3-4: Expansão adiabática reversível na turbina. $O$ vapor vindo da caldeira tem valores de temperatura e pressão elevados; ele se expande através da turbina para produzir trabalho, e então passa pelo condensador com uma pressão reduzida, desprezando as transferências de calor para a vizinhança e a variação da energia potencial e cinética do sistema. Uma análise do processo pela primeira lei da termodinâmica, tendo a turbina como volume de controle, pode ser dada pela equação (3):

$$
w_{34}=\left(h_{4}-h_{3}\right)
$$

Onde:

$\mathrm{w}_{34} \rightarrow$ Trabalho específico produzido pela turbina $[\mathrm{J} . \mathrm{kg} / \mathrm{s}$ ]

Processo 4-1: Transferência de calor em pressão constante no condensador. Nesta parte do sistema ocorre uma transferência de calor do fluido de trabalho para o sistema de arrefecimento. Em regime permanente, tal equacionamento pode ser dado pela equação (4):

$$
\boldsymbol{q}_{41}=\left(h_{1}-h_{4}\right)
$$

$\mathrm{q}_{41}$ é considerado negativo na análise, pois esse calor é perdido para o meio externo.

O trabalho líquido $\left(w_{l}\right)$ do ciclo é dado pela equação (5):

$$
w_{l}=w_{34}-w_{12}
$$

A eficiência do ciclo (y) é dada pela equação (6) e (7):

$$
\mathrm{\eta}=\frac{w_{l}}{q_{23}}
$$

ou

$$
\eta=\frac{\left(h_{4}-h_{3}\right)-\left(h_{2}-h_{1}\right)}{h_{3}-h_{2}}
$$


CARPIO, R. C. et al. Análise teórica da recuperação de calor para geração de energia em indústrias de cimento e cal utilizando o Ciclo de Rankine Orgânico

\section{CICLO RANKINE ORGÂNICO}

Para conversão de energia térmica de média e baixa temperatura em eletricidade, utiliza-se uma variação do CR, definido como Ciclo de Rankine Orgânico (CRO ou ORC - "Organic Rankine Cycle"). O funcionamento do ORC é semelhante ao CR tradicional; porém, no tocante ao fluido de trabalho a ser utilizado, o ORC utiliza fluidos orgânicos ao invés da água.

Como o Ciclo Rankine Orgânico é usado para recuperação de calor em baixas e médias temperaturas, geralmente utiliza-se um trocador de calor para aproveitar o fluxo térmico proveniente de processos industriais como fonte de calor, conforme pode ser verificado na FIG. 4.

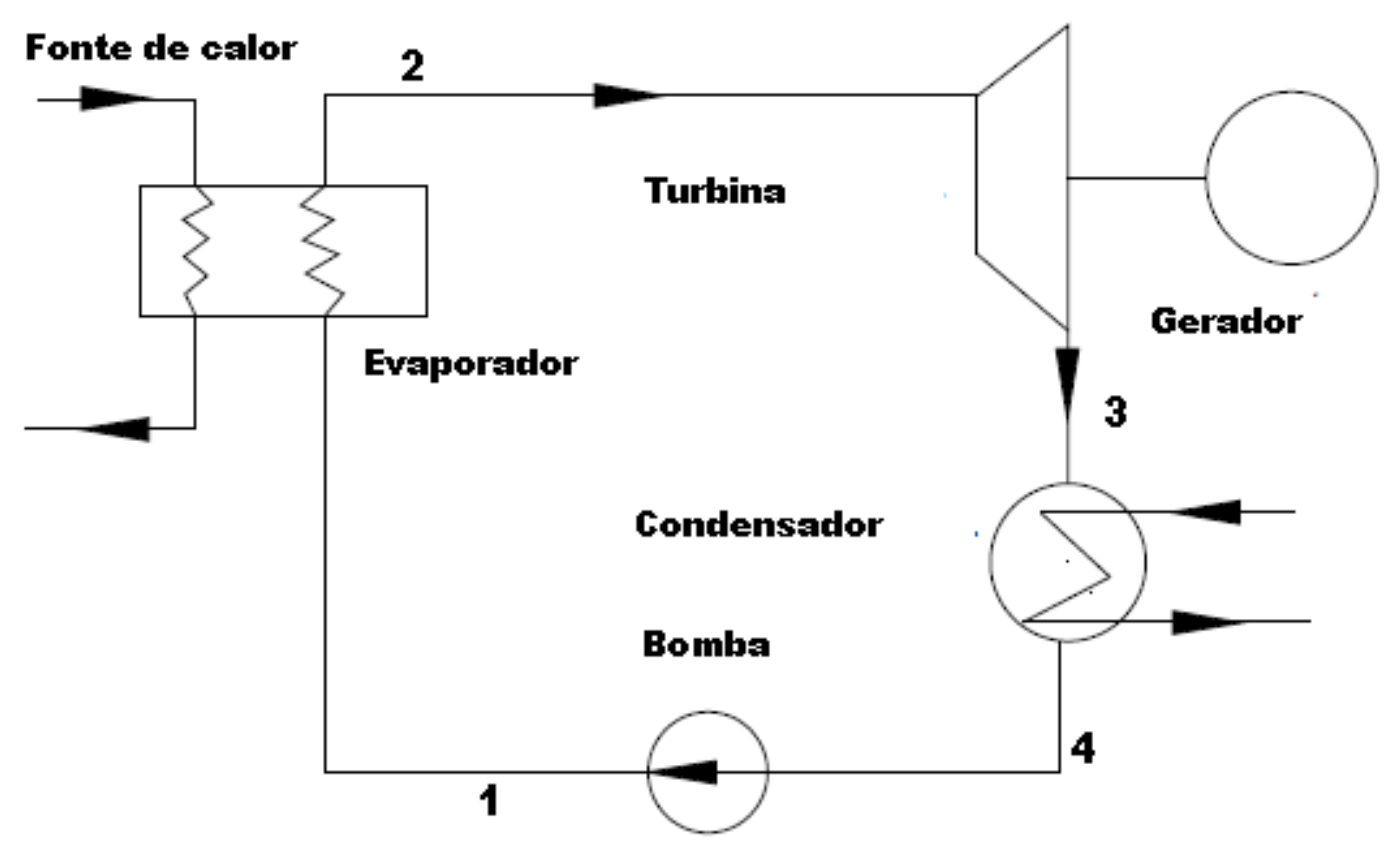

Figura 4 - Esquema do ORC

Fonte: Adaptado de Gao et al. (2012).

Podem-se considerar as seguintes vantagens ao se usar o ORC:

- Fluidos orgânicos possuem calor latente de vaporização menor que o da água, o que permite a circulação de uma maior vazão de fluido no circuito, aproveitando melhor a energia térmica. Uma menor queda de entalpia específica nas turbinas reduz danos à instalação e permite que, na maioria dos casos (capacidade da instalação inferior a 1-2 MW), um só estágio de expansão seja utilizado, diferentemente das instalações que usam vapor de água (LARJOLA, 1994). 
CARPIO, R. C. et al. Análise teórica da recuperação de calor para geração de energia em indústrias de cimento e cal utilizando o Ciclo de Rankine Orgânico

- Com parâmetros termodinâmicos, como baixas temperaturas e pressões, configurações do ciclo de Rankine que não são possíveis com a água podem ser verificadas (CARLÃO, 2010).

- Os níveis de pressão do fluido dentro dos vários componentes do ciclo não são totalmente dependentes da temperatura da fonte quente ou fria de calor (por exemplo, baixas temperaturas podem estar associadas a altas pressões, e altas temperaturas associadas a baixas pressões) (CARLÃO, 2010).

- Devido à inexistência de condensação do fluido, não é verificada erosão nas pás da turbina.

Apesar de possuir vantagens em médias e baixas temperaturas, a operação com baixos parâmetros termodinâmicos, como temperatura e pressão do ORC, implica em uma menor eficiência que a do ciclo a vapor tradicional, de modo que a cogeração é uma opção a ser considerada, visando aumentar a eficiência global do processo.

A Figura 5 mostra uma comparação entre o rendimento do ORC e outras máquinas térmicas para diferentes potências.

\section{Potência MW}

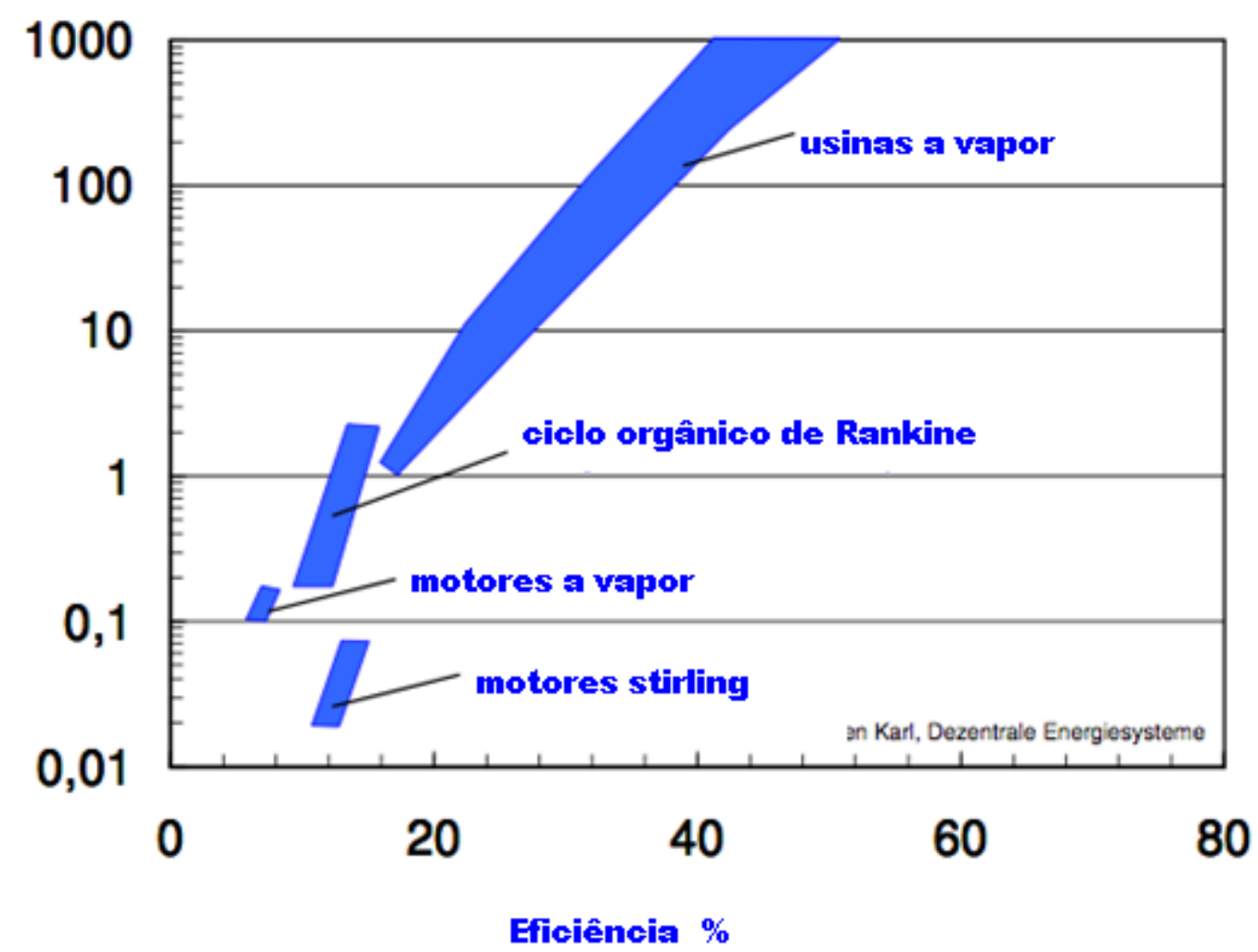

Figura 5- Comparação do rendimento do ciclo ORC e outras máquinas térmicas para diferentes potências Fonte: Spliethoff e Shuster (2006 apud CARLÃO, 2010). 
CARPIO, R. C. et al. Análise teórica da recuperação de calor para geração de energia em indústrias de cimento e cal utilizando o Ciclo de Rankine Orgânico

\subsection{Os fluidos de trabalho orgânicos}

A maior parte dos sistemas de potência a vapor utiliza a água como fluido de trabalho. Isso se deve ao fato de que a água apresenta um bom rendimento, conforme pode ser verificado na Figura 5. Além disso, ela é abundante, possui baixo custo, não é tóxica, é quimicamente estável e relativamente não corrosiva (SHAPIRO et al., 2005).

Os fluidos de trabalho do CRO podem ser divididos em três categorias: os úmidos, isentrópicos e secos. Tais nomenclaturas são dadas de acordo com a derivada da curva do diagrama $\mathrm{T}-\mathrm{S}(\mathrm{dT} / \mathrm{dS})$, que pode ser negativa, infinita ou positiva, respectivamente (LIU; CHIEN; WANG, 2002).

Para operar nos ciclos $\mathrm{CRO}$, os fluidos secos ou isentrópicos são preferíveis porque, após o processo de expansão, eles se mantêm sobreaquecidos. Isso gera uma maior eficiência e garante maior durabilidade das pás da turbina, pois não há presença de gotículas de líquidos na saída da turbina e, consequentemente, não há necessidade de equipamentos auxiliares para fazer o sobreaquecimento do vapor (LIU; CHIEN; WANG, 2002).

Gao et al. (2012) fizeram uma análise de 18 fluidos orgânicos, os quais podem ser verificados na TAB. 1.

Tabela 1- Propriedades de alguns fluidos orgânicos

\begin{tabular}{llclll}
\hline Substância & $\begin{array}{c}\text { Pressão } \\
\text { Crítica (MPa) }\end{array}$ & $\begin{array}{c}\text { Temperatura } \\
\text { Crítica (K) }\end{array}$ & $\begin{array}{c}\text { Temperatura } \\
\text { Mínima (K) }\end{array}$ & $\begin{array}{c}\text { Temperatura } \\
\text { Máxima (K) }\end{array}$ & $\begin{array}{c}\text { Pressão } \\
\text { Máxima } \\
\text { (MPa) }\end{array}$ \\
\hline R123 & 3,6618 & 456,83 & 166 & 600 & 40 \\
R245ca & 3,925 & 447,57 & 200 & 500 & 60 \\
R245fa & 3,64 & 427,20 & 200 & 500 & 60 \\
Butane & 3,796 & 425,13 & 134,87 & 589 & 69 \\
R236ea & 3,502 & 412,44 & 242 & 500 & 60 \\
R142b & 4,07 & 410,26 & 142,72 & 500 & 60 \\
Isobutene & 3,64 & 407,82 & 113,56 & 573 & 35 \\
R236fa & 3,2 & 398,07 & 179,52 & 500 & 40 \\
R124 & 3,624 & 395,43 & 120 & 470 & 40 \\
R152a & 4,5168 & 386,41 & 154,56 & 500 & 60 \\
R227ea & 2,926 & 374,80 & 146,35 & 500 & 60 \\
R134a & 4,059 & 374,21 & 169,85 & 455 & 70 \\
Propylene & 4,664 & 365,57 & 100 & 600 & 200 \\
R32 & 5,782 & 351,26 & 136,34 & 435 & 70 \\
R143a & 3,761 & 345,86 & 161,34 & 650 & 100 \\
\hline
\end{tabular}

ForSci.: r. cient. IFMG campus Formiga, Formiga, v. 3, n. 1, p. 18-30, jan./jun. 2015. 
CARPIO, R. C. et al. Análise teórica da recuperação de calor para geração de energia em indústrias de cimento e cal utilizando o Ciclo de Rankine Orgânico

\begin{tabular}{llllll}
\hline R218 & 2,671 & 345,10 & 113 & 500 & 30 \\
R125 & 3,617 & 339,17 & 172,52 & 500 & 60 \\
R41 & 5,897 & 317,28 & 175 & 500 & 60 \\
\hline
\end{tabular}

Fonte: Gao et al. (2012).

Segundo Gao et al. (2012), maiores temperaturas de entrada na máquina de expansão levam a um menor tamanho de turbina. Para alguns fluidos, como o R123, R124, R134a, o aumento da pressão de entrada gera um aumento no tamanho da máquina de expansão.

Em seu artigo, Gao et al. (2012) também citam que é difícil escolher um fluido de trabalho que possa satisfazer os requisitos - tanto da potência máxima quanto do investimento mínimo - bem como obter um tamanho reduzido de turbina. Os autores recomendam o uso dos fluidos R152a e R143a devido a fatores econômicos.

Liu, Chien e Wang (2002) mencionam o uso dos fluidos R245fa e R245ca por causa do baixo impacto ambiental que causam, como potencial de depleção da camada de ozônio e potencial de aquecimento global.

\subsection{A escolha dos fluidos}

A escolha do fluido de trabalho orgânico e os parâmetros de operação afetam diretamente a eficiência do sistema, devido às propriedades termodinâmicas de cada fluido (LIU; CHIEN; WANG, 2002).

Em relação a essa escolha, deve-se levar em consideração:

- A presença de ligações de hidrogênio em certas moléculas, como água, amônia e etanol, resulta em fluidos úmidos, por causa de uma maior entalpia de vaporização, e é considerada inadequada para sistemas ORC (LIU; CHIEN; WANG, 2002);

- Baixo custo e disponibilidade no mercado;

- A temperatura de operação deve estar dentro das permitidas por cada fluido. Diferentemente da água, fluidos orgânicos sofrem degradação e se tornam instáveis em altas temperaturas (CARLÃO, 2011).

- Os impactos ambientais gerados, como o potencial do efeito estufa e da destruição da camada de ozônio, toxicidade e inflamabilidade. 
CARPIO, R. C. et al. Análise teórica da recuperação de calor para geração de energia em indústrias de cimento e cal utilizando o Ciclo de Rankine Orgânico

\section{CONCLUSÃO}

Pode-se notar que a cogeração de energia elétrica por meio do ciclo Rankine Orgânico mostra-se uma forma promissora para o aproveitamento de fluxos térmicos rejeitados em processos industriais, como os de cimento e cal, principalmente em Minas Gerais, devido ao grande número de indústrias encontradas no estado. Segundo dados primários, a temperatura de escape de indústrias de cal na região tem valor médio de $120^{\circ} \mathrm{C}$. Em seu trabalho, Vicentini (2011) mostrou que, com uma temperatura de entrada de $90^{\circ} \mathrm{C}$, foi possível gerar um trabalho na turbina na ordem de $265 \mathrm{KW}$, para um fluxo térmico de $4.350 \mathrm{KW}$, o que indica uma viabilidade técnica na instalação de módulos ORC em algumas indústrias da região, sendo necessário realizar um estudo que contemple os aspectos econômicos do projeto.

Ao fazer o dimensionamento de uma máquina ORC, um dos principais parâmetros a serem estudados é o fluido de trabalho orgânico a ser utilizado, pois ele altera o rendimento do ciclo. Além disso, aspectos ambientais e de custo devem ser analisados.

\section{REFERÊNCIAS}

CARLÃO, R. L. L. Projecto de um ciclo de Rankine orgânico para produção de 200 kWe: (Relatório Mestrado). Portugal: Faculdade de Engenharia da Universidade do Porto, 2010 .

CARPIO, R. C. Otimização no co-processamento de resíduos na indústria do cimento envolvendo custos, qualidade e impacto ambiental. 2005. $174 \mathrm{f}$. Tese (Doutorado em Engenharia Mecânica) - Universidade Federal de Itajubá, Iatjubá, MG, 2005.

GALANIS, N. et al. Electricity generation from low temperature sources. Journal of Applied Fluid Mechanics, v. 2, p. 55-67, 2009.

GAO, H. Performance analysis and working fluid selection of a supercritical organic rankine cycle for low grade waste heat recovery. Energies. v. 5, p. 3233-3247, 2012.

EMPRESA DE PESQUISA ENERGÉTICA (EPE). Balanço energético nacional 2013: ano base 2012/Empresa de Pesquisa Energética. Rio de Janeiro: EPE, 2013.

LORA, E. E. S.; NASCIMENTO, M. A. R. Geração termelétrica: planejamento, projeto e operação. Rio de Janeiro: Interciência, 2004. v. 2.

LARJOLA, J. Electricity from industrial waste heat using high-speed organic Rankine cycle (ORC), Production Economics, v. 41, p. 227-235, 1994. 
CARPIO, R. C. et al. Análise teórica da recuperação de calor para geração de energia em indústrias de cimento e cal utilizando o Ciclo de Rankine Orgânico

LIU, B. T.; CHIEN, K. H.; WANG, C. C. Effect of working fluids on organic Rankine cycle for waste heat recovery. Energy, v. 29, p. 1207-1217, 2002.

REIS, L. B. Geração de energia elétrica, tecnologia, inserção ambiental, planejamento, operação e análise de viabilidade. Barueri, SP: Manole, 2011.

ROY, P. et al. Thermodynamic analysis of a power cycle using a low-temperature source and a binary $\mathrm{NH}_{3}-\mathrm{H}_{2} \mathrm{O}$ mixture as working fluid. International Journal of Thermal Sciences, v. 49 , p. 48-58, 2010.

SHAPIRO, H. et al. Introdução à engenharia de sistemas térmicos. Rio de Janeiro: LTC, 2005.

VICENTINI, M. C. Aplicação do Ciclo Rankine Orgânico alimentado termicamente pela queima da casca do arroz e resíduos de madeira. 2011. $63 \mathrm{f}$. Trabalho de Conclusão de Curso (Graduação em Engenharia Mecânica) - Faculdade de Engenharia do Campus de Guaratinguetá, Universidade Estadual Paulista, Guaratinguetá, 2011.

Recebido em: 11/07/2014

Aprovado em: 10/03/2015

Publicado em: 29/06/2015 